\title{
Enfoques narrativos en la investigación educativa brasileña ${ }^{1}$
}

\author{
Maria da Conceição Passeggi \\ mariapasseggi@gmail.com \\ https://orcid.org/0000-0002-4214-7700 \\ Universidade Federal do Rio Grande do Norte - UFRN \\ Universidade Cidade de São Paulo- UNICID
}

São Paulo, Brasil

Recibido: 11/05/2020 Aceptado: 19/05/2020

\section{Resumen}

El objetivo de esta reflexión es presentar las aperturas epistemológicas proporcionadas por los enfoques narrativos en el ámbito de la investigación cualitativa en Educación y más específicamente las direcciones que han tomado en Brasil. Para ello, consideraré como base los estudios que he realizado en los últimos veinte años y los caminos trazados junto con investigadores brasileños, europeos y de la latino-américa para la constitución del movimiento biográfico internacional. Presento, inicialmente, tres enfoques narrativos, en los que sitúo mi investigación: el de las historias de vida en formación (Pineau y Le Grand, 2012; Nóvoa y Finger, 2010; Dominicé, 2000), el de la investigación biográfica en la educación (DeloryMomberger, 2000; Peter Alheit, 2014) y el de la investigación (auto)biográfica (Passeggi, Souza, 2017; Abrahão, 2004). Trataré de discutir las afiliaciones de estos enfoques y me centraré, aunque sea brevemente, en dónde difieren y dónde coinciden. A continuación, examinaré los principios epistemológicos que subyacen a los tres tipos de apuestas que se infieren de estos planteamientos: una apuesta epistemopolítica, una apuesta descolonizadora y una apuesta pos disciplinaria, que sirven de base para esbozar lo que llamaré aquí paradigma narrativo-autobiográfico, centrado en la íntima relación entre "la vida, la experiencia vivida y la ciencia", tal como propone Dilthey (2010). Finalmente, discuto las promesas e incertidumbres del paradigma narrativo-autobiográfico, problematizando la forma en que la subjetividad (auto) entra muy tímidamente en la investigación educativa. Me centraré en algunas nociones arraigadas en la experiencia vivida por los actores sociales (adultos, jóvenes, niños), que justifican otra forma de considerar la singularidad y la subjetividad en los procesos educativos en una sociedad profundamente cambiante. Las consideraciones abiertas van en el sentido de destacar que el conocimiento producido en los enfoques constitutivos del paradigma narrativoautobiográfico está enraizado en la vida y en la defensa de la vida.

Palabras clave: Enfoques narrativos. Paradigma narrativo-autobiográfico. Experiencia vivida. Reflexividad.

\footnotetext{
${ }^{1} \mathrm{O}$ artigo vincula-se aos Projetos de pesquisa: (1) Passeggi, M. "Narrativa, educação e saúde: crianças, família e professores entre o hospital e a escola" (MCTIC/CNPq, Chamada no 28/2018, processo n. 443695/2018-0); (2) Passeggi, M. "Narrativas, educação, saúde: epistemologia e métodos da pesquisa (auto)biográfica com crianças". (MCTI/CNPq Chamada nº 06/2019 (processo n. 307063/2019-4).
} 


\title{
Abordagens Narrativas na Pesquisa Educacional Brasileira
}

\begin{abstract}
Resumo
O objetivo da presente reflexão é apresentar aberturas epistemológicas propiciadas pelas abordagens narrativas no âmbito da pesquisa qualitativa em Educação e mais especificamente os rumos que elas tomaram no Brasil. Para tanto, considerarei como base os estudos que conduzi, ao longo dos últimos vinte anos, e os caminhos traçados em conjunto com pesquisadores brasileiros, europeus e das Américas para a constituição do movimento biográfico internacional. Apresento, inicialmente, três abordagens narrativas em educação, nas quais situo as minhas pesquisas: a das histórias de vida em formação (Pineau e Le Grand, 2012; Nóvoa e Finger, 2010; Dominicé, 2000), a da pesquisa biográfica em educação (Delory-Momberger, 2000; Peter Alheit, 2014) e a da pesquisa (auto)biográfica (Passeggi, Souza, 2017; Abrahão, 2004). Procurarei discutir as filiações dessas abordagens e focalizarei, ainda que brevemente, em que diferem e em que coincidem. Discutirei em seguida, princípios epistemológicos subjacentes a três tipos de apostas que se depreendem dessas abordagens: uma aposta epistemopolítica, uma decolonizadora e uma aposta pós-disciplinar, que servem de fundamento para esboçar o que denominarei aqui de paradigma narrativo-autobiográfico, centrado na íntima relação entre "a vida, a experiência vivida e a ciência", conforme propõe Dilthey (2010). Finalmente, discuto promessas e incertezas do paradigma narrativo-autobiográfico, problematizando a forma como a subjetividade (auto) ingressa muito timidamente na pesquisa educacional. Focalizarei algumas noções enraizadas na experiência vivida dos atores sociais (adultos, jovens, crianças), que justificam uma outra forma de considerar a singularidade e a subjetividade nos processos educativos numa sociedade em profunda mutação. As considerações em aberto vão no sentido de destacar que os conhecimentos produzidos nas abordagens constitutivas do paradigma narrativo-autobiográfico se enraízam na vida e na defesa da vida.
\end{abstract}

Palavras-chave: Abordagens narrativas. Paradigma narrativo-autobiográfico. Experiência vivida. Reflexividade.

\section{Narrative approaches in Brazilian educational research}

\begin{abstract}
The objective of this reflection is to present epistemological openings, provided by narrative approaches in the scope of qualitative research in Education and more specifically the directions they have taken in Brazil. To this end, I will consider as a basis the studies that I have conducted over the last twenty years and the paths traced out together with Brazilian, European and American researchers for the constitution of the international biographical movement. I present, initially, three narrative approaches in education, in which I place my research: that of life stories in formation (Pineau and Le Grand, 2012; Nóvoa and Finger, 2010; Dominicé, 2000), that of biographical research in education (Delory-Momberger, 2000; Peter Alheit, 2014) and that of (auto)biographical research (Passeggi, Souza, 2017; Abrahão, 2004). I will try to discuss the affiliations of these approaches and will focus, even if briefly, on where they differ and where they coincide. I will then discuss the epistemological principles underlying three types of bets that are inferred from these approaches: an epistemopolitical bet, a decolonizing bet, and a postdisciplinary bet, which serve as a basis for outlining what I will call here a narrativeautobiographical paradigm, centered on the intimate relationship between "life, lived experience and science," as proposed by Dilthey (2010). Finally, I discuss the promises and uncertainties
\end{abstract}


of the narrative-autobiographical paradigm, problematizing the way the subjectivity (auto) enters very timidly into educational research. I will focus on some notions rooted in the lived experience of social actors (adults, youth, children), which justify another way of considering singularity and subjectivity in educational processes in a profoundly changing society. The open considerations go in the sense of highlighting that the knowledge produced in the constitutive approaches of the narrative-autobiographical paradigm is rooted in life and in the defence of life.

Keywords: Narrative approaches. Narrative-autobiographical paradigm. Lived experience. Reflexivity.

\section{Introdução}

O homem é um ser que se compreende interpretando-se, $e$ o modo pelo qual ele se interpreta é o modo narrativo.

Paul Ricœur ${ }^{2}$

A pesquisa qualitativa, na pluralidade de seus enfoques teórico-metodológicos, fundamenta os conhecimentos por ela produzidos na percepção de quem narra, seja de agentes sociais, seja de pesquisadores, sobre os modos como veem a vida e os mais variados fenômenos situados na diversidade de contextos histórico-culturais. A experiência vivida e narrada tornase pois a matéria prima, a fonte de investigação nas Ciências Humanas e Sociais. É nessa perspectiva, que ela propõe rupturas epistemológicas, há mais de um século, desde a publicação do consagrado livro de Thomas e Znanieck, em 1918, para o qual os autores recorreram às histórias de vida de imigrantes poloneses como um de seus instrumentos de pesquisa. Postas de lado por diversas razões, o uso dessa modalidade de narrativa pessoal, na pesquisa, ressurge, na Itália, com os trabalhos seminais de Franco Ferrarotti, que desde os anos 1950, propunha uma mirada crítica sobre as histórias de vida em Sociologia. Na França, são os estudos de Daniel Bertaux, iniciados nos anos 1970 em etnossociologia, que podem ser vistos como parte desse ressurgimento. Os dois autores, preocupados em demarcar esse novo momento, se afastam do termo histórias de vida. Ferrarotti (2014) propõe em substituição método biográfico e defende a sua autonomia como fonte primária de pesquisa. Bertaux (2010) prefere narrativas de vida (récits de vie), para o estudo das práticas (artesanais, profissionais) de grupos sociais.

Como afirma François Dosse (2009, p. 249), se Bertaux e Ferrarotti ,"malgrado suas divergências", conferem à narrativa da experiência vivida valores heurístico e hermenêutico,

\footnotetext{
${ }^{2}$ Paul Ricœur, 2010, p. 220.
} 
arrancando-a da situação de descarte nas considerações científicas, por mais de 30 anos, é nos anos 1980, que a virada narrativa opera uma mudança paradigmática nas ciências sociais e humanas. Pois, para além de se considerar a narrativa como um método de pesquisa, uma técnica de recolha de fontes em Sociologia, Psicologia Social, História Oral, por exemplo, que as utilizavam para se aproximar da concretude dos acontecimentos vistos e narrados por quem viveu e sofreu sob seus impactos, trata-se de compreender a natureza da narrativa como “instrumento mental de construção da realidade” e de si mesmo. É essa descoberta que constitui para Bruner (1991, p. 5) uma "mudança de paradigma”. A preocupação central volta-se para o ato de narrar e como ele intervém na cognição humana, envolvendo aspectos sociohistóricos, biológicos, psíquicos, sociais na interação da pessoa que narra com o outro e com o mundo humano. Para Ricœur (2010, p.220), que se alinha a essa mudança paradigmática, o humano "é um ser que se compreende interpretando-se, e o modo pelo qual ele se interpreta é o modo narrativo".

A comemoração dos 40 anos da Revista Paradigma me inspirou o desejo de retraçar, para este número especial, uma síntese, ainda que imperfeita e provisória, de 40 anos do que chamarei de paradigma narrativo-autobiográfico na pesquisa qualitativa em educação. Para tanto, discutirei neste artigo três abordagens narrativas que se entrecruzam e se enriquecem mutuamente: a das histórias de vida em formação (Pineau e Le Grand, 2012; Nóvoa e Finger, 2010; Dominicé, 2000), a da pesquisa biográfica em educação (Delory-Momberger, 2000, 2005, 2014; Alheit; Daussien, 2006) e a da pesquisa (auto)biográfica (Passeggi, Souza, 2017; Abrahão, 2004). Essa entrada permitirá esboçar, na sequência, princípios epistemológicos subjacentes a três tipos de apostas que se depreendem dessas abordagens: uma aposta epistemopolítica, uma aposta decolonizadora e uma aposta pós-disciplinar, que servem de fundamento para esboçar o que denominarei aqui de paradigma narrativo-autobiográfico, ancorado na íntima relação entre "a vida, a experiência vivida e a ciência", conforme propõe Dilthey (2010). Finalmente, discuto promessas e incertezas do paradigma narrativoautobiográfico, problematizando a forma como a subjetividade ingressa muito timidamente na pesquisa educacional. Focalizarei algumas noções enraizadas na experiência vivida dos atores sociais (adultos, jovens, crianças), que justificam uma outra forma de considerar a singularidade e a subjetividade nos processos educativos numa sociedade em profunda mutação. As considerações em aberto vão no sentido de destacar que os conhecimentos produzidos nas 
abordagens constitutivas do paradigma narrativo-autobiográfico se enraízam na vida e na defesa da vida.

\section{Abordagens narrativas em educação}

O indivíduo não é um sujeito por decisão divina, mas pelo esforço de se libertar de restrições e regras para organizar sua experiência. Ele é definido por sua liberdade e não por seus papéis.

Alain Touraine ${ }^{3}$

Para quem se inicia na pesquisa qualitativa com enfoques biográficos e/ou autobiográficos em educação, é difícil deslindar confluências e divergências entre as mais diversas abordagens. Souza, Serrano y Ramos (2014, p. 684) consideram que "lo biográfico se ha convertido en el epítome de las ciencias sociales modernas y del saber educativo en general". Então, por que discutir em que diferem ou se assemelham essas abordagens? Por que indagar suas filiações e ramificações na extensa produção científica em educação? Trata-se apenas de vislumbrar, como já mencionei, de retraçar o percurso histórico, no Brasil, e mais precisamente, nos últimos quase $30 \operatorname{anos}^{4}$, das histórias de vida em formação, da pesquisa biográfica em educação e da pesquisa (auto)biográfica.

Essas três abordagens trazem indícios de suas filiações e propósitos na forma como se dão a conhecer. A primeira delas opta por histórias de vida; a segunda por pesquisa biográfica e a terceira por pesquisa (auto)biográfica. $\mathrm{O}$ foco da primeira recai sobre a formação (histórias de vida em formação), o da segunda sobre a educação (pesquisa biográfica em educação), o foco da terceira é duplo: introduz o (auto) para sinalizar a presença da subjetividade em pesquisa e omite formação e educação, deixando o campo aberto para ambas.

Histórias de vida em formação. Essa primeira abordagem narrativa emerge nos anos 1980, há 40 anos, em universidades e centros de formação na França, Bélgica, Suíça, Canadá (Québec) e Portugal, no âmbito da formação permanente, ou continuada de adultos, institucionalizada no início dos anos 1970. Centrada na formação de formadores que deviam formar quem buscava (re)orientação profissional, ela nasce, como lembra Pineau (2006, p. 331), com os objetivos de explorar "o continente obscuro da autoformação ao longo da vida" e de

\footnotetext{
3 Tourraine (1992, p. 178).

${ }^{4}$ Tomo como marco o artigo de Bueno, Catani, Souza, Sousa (1993) em que associam interpretações autobiográficas e formação de professores.
} 
coinvestir em saberes experienciais na validação da experiência adquirida e na (re)construção de projetos de vida 5 .

É nesse sentido, que o termo em formação permite demarcar, segundo Dominicé (2010, p. 179), a preocupação em "alcançar uma teoria da formação" ainda não explorada, ou inexistente. Nesse sentido, a pessoa em formação é concebida, ao mesmo tempo, como ator social e pesquisador de sua própria experiência. Como ator social, trata-se de contar e de refletir sobre seu percurso educativo; como pesquisador de investigar, compreender e sistematizar os processos de formação. Criam-se assim "condições para que a formação se faça na produção do saber e não, como até agora, no seu consumo" (Nóvoa, 2010, p.154). Essa mirada epistemológica, permite diferenciar o uso das histórias de vida como técnica ou instrumento de pesquisa, diferentemente do se faz em outras ciências, seja para a (re)construção de acontecimentos históricos (História Oral), seja para a compreensão de fenômenos, atitudes sociais ou culturais (Sociologia, Psicologia Social, Antropologia). Em educação, as histórias de vida em formação servem principalmente para quem se forma. Nesse sentido, um dos conceitos primordiais dessa abordagem é o de pesquisa-formação, em que o traço de união entre os dois termos torna indissociável a formação da reflexão investigativa (Pineau, 2005; Dominicé, 2000; Josso, 2010; Passeggi, 2016).

Alternam-se nessa abordagem as noções de histórias de vida e biografia educativa para se referir às narrativas escritas pelos adultos, formadores, em formação. A opção por histórias de vida busca evitar a vinculação com a grafia (presente em autobiografia) e com o eu (auto) para focalizar a vida (bios) (Pineau; Le Grand, 2010). A Escola de Genebra (Dominicé, 2000; Josso, 2010; Finger, 2014) opta por biografia educativa para sinalizar que o foco da escrita se concentra mais no percurso educativo do que na globalidade da vida. Por sua vez, a interação entre pares e com o formador, durante o processo de escrita, retiraria zonas mais pessoais ou intimista do eu (auto), daí a preferência por biografia educativa, entendendo a biografia como escrita (grafia) da vida (bios), numa perspectiva dialógica e coletiva. Para Pineau (2006, p.341), esse modelo "interativo ou dialógico" pressupõe que a construção de sentido não é nem redutível

${ }^{5}$ A vasta produção científica desta primeira abordagem se encontra concentrada na coleção Histoire de vie en formation (L'Harmattan), dirigida por Gaston Pineau, e em muitos números da Revista Éducation Permanente. 
à consciência ( ou ao inconsciente) de quem narra, nem à análise de quem lê (pesquisador), ela emerge na interação social no ato de narrar.

As histórias de vida em formação tornam-se uma referência em educação, no Brasil, a partir dos anos 1990, graças ao livro de António Nóvoa e Matthias Finger, publicado em 1988, em Portugal, e reeditado no Brasil em 2010, 2014. Durante 20 anos, o livro circulou entre nós sob a forma de cópias de livros já copiados, o que dificultava o seu acesso. O livro, reeditado no Brasil em 2010, reunindo artigos dos pioneiros das histórias de vida em formação ${ }^{6}$, se tornou uma referência incontornável para a pesquisa e a prática pedagógica na formação inicial e continuada de professores.

A pesquisa biográfica em educação é a segunda abordagem narrativa que virá contribuir para os estudos e as pesquisas em educação, com base nas experiências vividas e narradas, a partir dos anos 2000. A Recherche biographique en Éducation é proposta por Delory-Momberger (2000, 2003, 2005), na França, no inicio dos anos 2000. Como já dissemos anteriormente, ao invés de centrar-se no âmbito da formação, ela amplia as indagações para as relações que os indivíduos estabelecem com as instituições escolares: "Como se encontram o mundo de experiências, figuras e expectativas que a criança, o jovem e o adulto em formação trazem consigo, e o mundo de conhecimento que as instituições educativas propõem?" (DeloryMomberger, 2014, p. 25). A autora se situa dentro de um escopo desenvolvido na Alemanha, seu país de adoção. De modo que ela filia a pesquisa biográfica em educação à tradição alemã da Biographieforschung e a faz remontar aos estudos de Wilhelm Dilthey (1833-1911) que, como se sabe, propõe o paradigma compreensivo (qualitativo) nas Ciências Humanas, em oposição ao paradigma explicativo (positivista) das Ciências Naturais.

Dilthey coloca no centro de sua reflexão sobre a ciência histórica, as modalidades pelas quais o homem se apropria de sua própria vida, fazendo da reflexividade autobiográfica o paradigma do "compreender" (Versthehen) e da autobiografia o modelo hermenêutico "das ciências humanas" (Delory-Momberger, 2005, p. 36, grifos da autora, tradução minha).

A entrada do biográfico em educação, em língua alemã, também acontece no limiar dos anos 1980. Delory-Mombereger (2005) lembra que Dieter Baake e Theodor Shulze (1979), em seu livro, Aprender a partir das histórias, articulam os conceitos de narrativa, aprendizagem,

\footnotetext{
${ }^{6}$ Gaston Pineau e Adèle Chêné (Canadá), Pierre Dominicé, Marie-Christine Josso e Matthias Finger (Suíça), António Nóvoa (Portugal).
} 
experiência e formação, noções chave da investigação biográfica. Para Shulze (1993) a aprendizagem é uma experiência interior, ao ser narrada ela traz informações para uma pedagogia de orientação biográfica.

Nessa direção, os estudos de Christine Delory-Momberger (2000, 2003, 2005, 2014, 2019) se caracterizam por seu profundo investimento na demarcação da pesquisa biográfica em educação, como uma vertente da pesquisa qualitativa, de uma pedagogia biográfica ou de um paradigma biográfico, na elaboração de um referencial teórico e conceitual para traduzir a capacidade antropológica pela qual o humano percebe e organiza sua vida em termos de uma razão narrativa. Esse trabalho biográfico, ou de biografização, mediante o qual o humano se torna quem ele é, torna-se um dos principais foco dos estudos de Christine Delory-Momberger, que assume a tarefa de fazer da pesquisa biográfica um campo de investigação, com princípios epistemológicos, nocionais métodos de investigação e de análise, daí o interesse do conjunto de sua obra para a compreensão e aprofundamento do uso que se faz de narrativas biográficas e autobiográficas na investigação científica.

A pesquisa (auto)biográfica é a terceira abordagem narrativa. Ela nasce, no Brasil, com essa denominação, em 2004, por ocasião do primeiro Congresso Internacional de Pesquisa (Auto)Biográfica (I CIPA, Porto Alegre), idealizado por Maria Helena Menna-Barreto Abrahão (Abrahão, 2004), que reuniu pesquisadores da Europa, Canadá, Ásia, Estados Unidos da América e Brasil em torno do biográfico e do autobiográfico. O CIPA, hoje na sua nona edição ${ }^{7}$, se torna o marco inaugural e fórum de debates do movimento biográfico no Brasil, que passou a contar com a liderança de Elizeu Clementino de Souza ${ }^{8}$, desde 2006, quando realizou, em Salvador, o II CIPA. O movimento continua a se fortalecer pela interação entre redes de pesquisa nacionais e internacionais e a ampliar seu escopo, o que se vê nos 6 (seis) eixos do congresso, a saber: 1)Dimensões epistemológicas e metodológicas da pesquisa (auto) biográfica; 2) Espaços formativos, memórias e narrativas; 3) Infâncias, narrativas e diálogos intergeracionais; 3) (Auto)biografias, narrativas digitais, história, literatura e artes; 4) Escrita de si, resistência e empoderamento; 6) Histórias de vida, gênero e diversidades.

\footnotetext{
${ }^{7}$ O IX CIPA se realizará na Universidade de Brasília em 2021.

${ }^{8}$ Destaco a grande contribuição de Elizeu Clementino de Souza na criação, em 2008, da Associação Brasileira de Pesquisa (Auto)Biográfica - BIOgraph < https://www.biograph.org.br/> e da Revista Brasileira de Pesquisa (auto)Biográfica - RBPAB (Qualis 3) < https://www.revistas.uneb.br/index.php/rbpab >
} 
Qual o sentido do (auto) entre parênteses nessa abordagem com relação às duas primeiras? O (auto)biográfico é utilizado pela primeira vez no livro de António Nóvoa e Matthias Finger (2014) e aparece sempre associado a método: “O método (auto)biográfico e a formação"9 . O livro traz o texto de Franco Ferrarotti sobre "método biográfico" em sociologia ${ }^{10}$, mas não encontrei no livro, salvo engano, as razões do (auto). Em 2016, numa dessas raras ocasiões tive a oportunidade de viajar ao lado do Professor António Nóvoa, num voo entre Porto Alegre e Santa Maria. Pedi-lhe que me esclarecesse essa opção. Tratava-se para ele de um assunto sobre o qual não havia investido há muitos anos ${ }^{11}$. A intenção, em 1988, do (auto) deviase ao aspecto subjetivo que o método biográfico adquiria em educação, ausente em sociologia. Os parênteses podiam também sinalizar que a subjetividade não era vista na perspectiva intimista do eu, uma vez que o foco do método estaria nas aprendizagens, no conhecimento de si e do outro e na transformação individual de quem se forma. No interior do livro, permanece a equivalência: "histórias de vida ou método (auto)biográfico" (Nóvoa, Finger, 2010, pp. 16, $151,169,172)$.

Para Maria Helena Abrahão ${ }^{12}$, que concebe, no Brasil, o I Congresso Internacional de Pesquisa (Auto)Biográfica (I CIPA, 2004), a escolha do termo pesquisa se justificava para sinalizar o caráter científico do uso de narrativas em educação, questão crucial para sua legitimidade no começo da "aventura (auto)biográfica". Por sua vez, o uso dos parênteses se referia, ao mesmo tempo, às narrativas biográficas e autobiográficas e chamar a atenção para a subjetividade na pesquisa. Por fim, eles podem ainda remeter à transposição de narrativas autobiográficas para biográficas, isso acontece quando o pesquisador transforma uma narrativa autobiográfica (oral ou escrita), que lhe foi oferecida por um participante, que narra sua vida, numa narrativa biográfica ${ }^{13}$, em que o pesquisador assume a autoria do texto.

\footnotetext{
${ }^{9}$ O livro foi reeditado no Brasil em 2010 e em 2014.

${ }^{10}$ Cf. Ferrarotti, "Sobre a autonomia do método biográfico" (2010, p. 31-58).

${ }^{11}$ De fato, em 2009, quando o Professor Nóvoa concordou com a reedição do livro no Brasil, ele sugeriu que só se justificaria se fosse considerada "como um clássico" e não como livro recente. Seu comentário inspirou a criação da série "Clássicos das Histórias de vida", que coordeno com Elizeu Clementino de Souza e Christine DeloryMomberger, publicada pela Editora da Universidade Federal do Rio Grande do Norte (Edufrn). Agradeço ao Professor António Nóvoa a entrevista informal que me concedeu e espero que minha memória não nos tenha traído. 12 Agradeço a Maria Helena Menna-Barreto Abrahão pelas horas de discussão em torno da pesquisa (auto)biográfica quando do estágio de pós-doutorado que realizei com ela na PUCRS, em 2011-2012.

${ }^{13} \mathrm{Cf}$., por exemplo, capítulos do livro Destacados educadores brasileiros: suas histórias nossa história. organizado por Abrahão (2016).
} 
O que se observa é que, talvez por transferência, os parênteses são deslocados e de forma, às vezes, aleatória para "narrativas (auto)biográficas", sem que se explique a razão desse uso. Posso ter contribuído para esse uso, quando propus diferenciar a narrativa (auto)biográfica (oral ou escrita) das “escritas de si”, que se caracteriza como uma produção escrita (Passeggi, 2010). O que desejo defender a favor do auto (sem parênteses) é o percurso histórico dos 13 séculos que separam o termo biografia (Séc. V) da criação do termo autobiografia, que só surge entre os séculos XVIII e XIX (Pineau e Le Grand, 2012). Essa criação faz parte do processo civilizatório, que "autoriza" a inclusão e legitima o eu (auto) em Literatura. A culpa é de Rousseau! Para Dilthey (2010, p.177), "Rousseau quer alcançar sobretudo o direito ao reconhecimento de sua existência individual". A revolução causada por As Confissões, publicado entre 1782 e 1789, é a do eu, que se coloca a nu diante de seus contemporâneos, contrariamente às Confissões, de Sto. Agostinho, em que o autor se confessa a Deus. A revolução proposta por Rousseau é a de que o cidadão comum também pode escrever sobre a própria vida.

A "autobiografia", como se sabe, é um gênero consagrado em Literatura, cujas condições de escrita diferem daquelas praticadas nas abordagens aqui apresentadas, por essa razão evito usar o termo autobiografia. A profusão de termos encontrados na produção científica nessas três abordagens, continua a crescer à medida em que se aprofundam estudos e se diversificam as pesquisa. É o que me leva a optar pela narrativa, como o termo mais abrangente, e pelo adjetivo autobiográfica, para demarcar sua especificidade no amplo universo das narrativas.

É importante sublinhar que a pesquisa (auto)biográfica, no Brasil, nasce híbrida, múltipla, diversa. Ela se inspira nas duas primeiras abordagens e cresce com a contribuição de pesquisas em diversas áreas do conhecimento que com elas se identificam: história oral, sociologia, saúde, literatura, artes, formação de professores etc. Podemos melhor compreender essa diversidade dentro do espírito comunitário, ou seja o da partilha, da convivência e da coexistência das diferenças que se enriquecem mutuamente e que opera na e contra os perigos de hegemonias, catequeses e tabus. É nesse sentido que entendo a especificidade das abordagens narrativas abordadas, inclusive a de outras vertentes que não pude discutir aqui como é o caso da investigación biográfico-narrativa, desenvolvida por pesquisadores de países iberoamericanos (Bolívar, Segovia, 2019; Suárez, 2014), cuja força se evidencia no recém-lançado 
Programa de Doctorado en Investigación Narrativa y Autobiográfica en Educación, oferecido pela Universidad Nacional de Rosario, e coordenada pelos profesores Luis Porta e Daniel Suárez na cidade de Mar del Plata, na Argentina. A primeira promoção (2019) acolhe 100 estudantes provenientes da Argentina, Colômbia, Chile, Uruguai, México, Brasil e Equador. A outra abordagem é a da narrative inquiry e da biographical researche de orientação anglo-saxônica ${ }^{14}$.

Que pontos em comum partilham todas elas? Em primeiro lugar, a defesa de que as narrativas autobiográficas são suscetíveis de propiciar à pessoa que narra um processo de reinvenção de si, na direção da autonomia e de empoderamento (formação). Em segundo lugar, o reconhecimento de seu valor heurístico como método de pesquisa científica para a compreensão dos processos de formação ao longo da vida (life learning) e em todos aspectos da vida (lifewide learning). Essa virada paradigmática enfatiza, sobremaneira, a complementaridade das histórias de vida em formação, da pesquisa biográfica em educação e da pesquisa (auto)biográfica, o que permite pensar num paradigma narrativo-autobiográfico que religue a vida (bio), as reinveções de si (auto) e o discurso científico (grafia).

\section{Paradigma narrativo-autobiográfico em educação}

A autobiografia é a forma mais elevada e mais instrutiva, na qual a compreensão da vida vem ao nosso encontro.

Wilhelm Dilthey ${ }^{15}$

Thomas Kuhn (1922-1996), em seu livro A estrutura das revoluções científicas, publicado em 1962, afirma: “Considero 'paradigmas' as realizações científicas universalmente reconhecidas que, durante algum tempo, fornecem problemas e soluções modelares para uma comunidade de praticantes de uma ciência" (Kuhn, 1997, p.13). Ao associá-los à comunidade científica, Kuhn caracteriza a natureza das ciências como construções sociais, históricas, culturais, desmitificando sua objetividade e neutralidade para "alcançar a verdade". Os paradigmas emergem, se estabilizam, entram em crise, são abandonados com a emergência de um novo paradigma e a adesão da comunidade científica.

\footnotetext{
${ }^{14}$ Para uma percepção mais abrangente dessas abordagens, a Revista Brasileira de Pesquisa (Auto)Biográfica publicou diferentes dossiê sobre esses enfoques em diferentes continentes: Dossiê sobre Europa e América (n.9, 2018); Dossiê sobre a América Latina (n.8, 2018); Dossiê sobre a Ásia (n.12, 2019) <https://www.revistas.uneb.br/index.php/rbpab>

${ }^{15}$ Dilthey, 2010, p.178.
} 
Para Dilthey (2010, p. 95), "Vida, experiência de vida e ciências humanas encontramse, assim, em uma conexão interna estável e em uma relação de reciprocidade". Se isso é verdade, trata-se de perguntar: Por que razão se demorou tanto tempo para se considerar a vida, a experiência de vida e a reflexão sobre elas nas ciências da educação? Se a educação intervém para provocar mudanças, como compreendê-las sem passar pelas narrativas de quem aprende, onde maturam saberes, quereres, deveres e poderes. Narrar é preciso! Escutar ainda mais.

Essas questões estão na base da virada narrativa nos anos 1980, tributária do esgotamento de paradigmas dominantes nas ciências humanas e sociais em vigor nos anos 1960, que tendiam a descartar o sujeito e sua capacidade de reflexividade, de tomada de consciência de si e do poder de resistência e emancipação. Do ponto de vista sociológico, foi necessário o reconhecimento de movimentos sociais organizados, que explodem em 1968 e passam a operar a favor das rupturas com esses paradigmas. Como afirma Alain Touraine (1977, p. 67), as reivindicações desses movimentos obrigaram as ciências sociais a escutar o que os estudantes, mulheres, migrantes, ecologistas tinham a dizer e a encontrar novas formas de pesquisa de modo a serem "capazes de dar voz aos "analisados" e de ser usada "em benefício dos dominados". A reflexão de Touraine sobre essa inflexão paradigmática é antes de tudo provocadora quanto a quem detém o saber-poder sobre temas tão delicados e tão humanos em ciências? Afinal para quem, ou a quem, servem as ciências humanas e sociais? Uma mirada ética problematiza os paradigmas adotados não apenas quanto à sua produção científica, mas sobre os impactos sociais da pesquisa. Trata-se então de encontrar formas mais legítimas para escutar e fazer ouvir o que dizem as pessoas "comuns" sobre a vida e as experiências vividas no cotidiano. Essa preocupação marca a "virada narrativa" como parte da solução do problema.

Para Brockmeier e Harré (2003, p. 526), “a origem do interesse pela narrativa nas ciências humanas parece ser a “descoberta”, na década de 1980". Por essa razão, as narrativas orais e escritas tornam-se "um parâmetro linguístico, psicológico, cultural e filosófico fundamental para nossa tentativa de explicar a natureza e as condições de nossa existência". Como afirmava Barthes, em meados dos anos 1960, a narrativa "começa com a própria história da humanidade e nunca existiu em nenhum lugar e em tempo nenhum, um povo sem narrativa". Sua universalidade é visível na infinita diversidade de seu uso nas práticas humanas: narrativas jurídicas, literárias, bíblicas, históricas, científicas, ficcionais, anedóticas, jornalísticas, midiáticas, ideológicas, folclóricas, políticas, digitais etc. 
É dentro dessa infinita variedade de narrativas, que a pesquisa (auto)biográfica faz um recorte e opta pelas narrativas biográficas e autobiográficas como objeto de investigação. A noção de biografização substitui a noção de narração para demarcar melhor o campo científico. Deriva dessa noção duas outras a de autobiografização e de heterobiografização. Esta última se refere ao que aprendemos com a experiência do outro, contada oralmente ou por escrito. Admito que, do ponto de vista ontológico, os processos de heterobiografização precedem os outros dois. A criança aprende a narrar sua história com base nas estruturas e interpretações das narrativas que escuta. Na vida do adulto não é diferente. Provém daí a "potencialidade didática" das narrativas (experienciais, bíblicas, folclóricas, mitológicas, literárias, midiáticas, jurídicas etc.), pois são elas que dão acesso, e também moldam (formam, deformam) as narrativas de si. Somos, historicamente, o emaranhado de histórias que (ou)vimos/lemos/narramos ao longo de nossas vidas. A importância da reflexividade narrativa, quando ela se torna crítica, é permitir o devido distanciamento hermenêutico para efetuar a travessia que promove a consciência histórica e da historicidade para nos afirmar como seres sociais singulares.

Delory-Momberger, guiada por preocupações epistemológicas, terminológicas e nocionais, dirigiu recentemente uma obra monumental, o Vocabulaire des Histoires de Vie et de la Recherche Biographique (Érès, 2019), reunindo pesquisadores de abordagens narrativas (Histoires de vie en formation, Recherche biographique, Pesquisa (auto) biográfica, Investigación biográfico-narrativa, Biographical researche, Biographieforschung) na Europa e nas Américas, para elaborar as diferentes entradas sobre: noções, procedimentos de pesquisa; campos de atuação; correntes teóricas; práticas de formação. Trata-se de interrogar a experiência humana na sua complexidade: ao mesmo tempo antropológica e histórica; social e psíquica; educativa e política.

Há narrativa autobiográfica, quando a pessoa que narra faz uma reflexão sobre sua própria vida e a experiência vivida, geralmente, escrita na primeira pessoa: eu (auto). Há narrativa biográfica, quando o foco da narrativa recai na vida e na experiência de outrem, em geral, escrita na terceira pessoa (ele, ela, eles elas) atenuando-se a presença de quem narra. A vantagem das noções de narrativa autobiográfica, narrativa da experiência, narrativa de vida é, por um lado, a sua abrangência. Elas incluem todas as modalidades de narrativas de si: autobiografias, histórias de vida, biografias educativas, diários, memoriais, depoimentos, relatos... Por outro lado, elas podem variar de extensão sem perder a sua essência. Bertaux 
(2010, p. 18, grifos do autor) define uma concepção minimalista de narrativa: "existe narrativa de vida desde que haja descrição sob forma narrativa de um fragmento da experiência vivida".

Com base no que venho argumentando, são três as aposta e muitos os desafios e incertezas do paradigma narrativo-autobiográfico: uma aposta epistemopolíitica, uma aposta decolonizadora e uma aposta pós-disciplinar.

Aposta epistemopolítica. O neologismo, criado por Pineau e Le Grand (2012), sugere que a epistemologia deve ser indissociável de uma visão política na pesquisa educacional. É por essa razão que se aposta no reconhecimento e legitimidade da capacidade humana, da infância à adultez, de fazer uso da reflexividade autobiográfica sobre o que acontece e o que nos acontece. Para Paulo Freire (1992), subestimar o conhecimento que necessariamente resulta da reflexão sobre a experiência sociocultural dos indivíduos é tanto um erro científico quanto a manifestação equivocada de uma ideologia elitista em ciência. Afinal, para quem serve a prática dessa reflexividade sobre si e sobre a vida? Para o pensamento latino-americano (Reis; Domingos, 2013) há um consenso sobre o que se chamou de educação conscientizadora ou libertadora, proposta por Paulo Freire, no início dos anos 1960, há quase 60 anos, se caracteriza como uma (r)evolução paradigmática que nasce na sua concepção de prática pedagógica para inspirar politicamente atitudes reivindicatórias nas ciências sociais e humanas comprometidas com a transformação social com base na liberação de amarras e de empoderamento, contra a noção de sujeito assujeitado, seja ao determinismo social, seja ao inconsciente.

Assim como para Dominicé (2010), a formação serve primeiramente para quem se forma, tenho a convicção de que a pesquisa educacional serve primeiramente para quem narra e para quem pesquisa pela interação dialógica entre eles o mundo da vida e a sistematização científica. Só depois é que esse conhecimento serve para a ciência e a comunidade científica, que o avalia e coloca a serviço da sociedade. Admitir a legitimidade desse percurso é per se provocador de rupturas com paradigmas anteriores, que centrava a primazia da ciência e não a das pessoas que fazem a ciência. Considero que essa mudança de atitude se justifica para evitar que jovens pesquisadores sejam induzidos a esquecer a finalidade humana e a perspectiva ética da pesquisa, ao priorizar o método, os instrumentos, os resultados da pesquisa, por vezes, a obtenção de prêmios ou de grau acadêmico. Defendo a tese segundo a qual o centro da pesquisa é essa interrogação sobre a conectividade entre a pessoa (auto), a vida (bio) e o discurso das ciências (grafia). 
A aposta decolonizadora está intimamente articulada com a primeira, pois ela é igualmente política, no sentido em que visa romper as amarras de paradigmas anteriores que impedem avançar na direção dessa conectividade entre a pessoa (auto), a vida (bio) e o discurso científico (grafia). Para Bruner (1997, p. 27), a produção do conhecimento provém de dois modos de pensamento: o modo paradigmático (lógico-científico) e o modo narrativo (subjetivo). O primeiro se esforça para atingir o ideal de um sistema formal de descrição e explicação. $\mathrm{O}$ segundo tenta situar narrativamente as experiências, articulando um duplo ponto de vista: uma paisagem externa que é a da ação e uma paisagem interna que é a da consciência, da intencionalidade, da memória: "O que sabem as pessoas sobre a vida? O que dizem sobre ela? O que fazem nela, por ela, contra ela?

O modo paradigmático estaria em consonância com a epistemologia consagrada pela ciência moderna em seu esforço de desmistificar dogmas para alcançar a verdade, apoiando-se na produção de evidências lógicas e/ou empíricas. O modo narrativo, por sua vez, estaria enraizado no mesmo princípio de inteligibilidade narrativa sobre o qual Dilthey fundou uma epistemologia compreensiva e não explicativa das ciências humanas. A distinção de Bruner entre os modos paradigmáticos e narrativos pode ser aproximada da proposta de Boaventura de Sousa Santos (2002) entre uma "epistemologia do Norte" (paradigmática) e uma "epistemologia do Sul" (narrativa), pós-colonial ou decolonizadora. Pois para Santos (2002), "a ciência moderna consagrou o homem como sujeito epistêmico, mas o expulsou como sujeito empírico". É com base nessa dicotomia que se opõe, ou se dá primazia ao sujeito racional e abstrato, e se descarta o sujeito empírico ou da experiência na pesquisa científica, exigindo-se a separação do eu (auto) de carne e osso; da vida (bios) e da narrativa cientifica (grafia).

O paradigma narrativo-autobiográfico, adota fundamentalmente o modo narrativo e se caracteriza como uma epistemologia do Sul, pela legitimidade e respeito a quem narra. Seria ilógico, se a ciência procurasse ouvir a maioria silenciosa, ou silenciada, cuja palavra é socialmente negada, para excluir do seu discurso essa palavra, ou nada fazer por quem narra. Esses questionamentos são válidos para interrogar a forma como os dois modos de pensamento estão presentes, e em graus diferentes, na pesquisa. A vitalidade do paradigma narrativoautobiográfico em educação se deve sem dúvida ao fato de que ele abre oportunidades para se aprender com o Sul. 
A aposta pós-disciplinar, que aqui defendo, se inspira no pensamento de Franco Ferrarotti (2014), em suas reflexões sobre a autonomia do método biográfico nas ciências sociais. Para Ferrarotti, o ser humano constrói um conhecimento global e holístico sobre si mesmo e sua sociedade, por essa razão o autor se aproxima dos Estudos culturais:

[...] o método biográfico e os Cultural studies encontram-se numa mirada comum, eles estão para além das divisões disciplinares. Nem multi, nem inter, nem transdisciplinar, mas pós-disciplinar. Isso quer dizer que é preciso ir buscar instrumentos heurísticos e metodológicos no lugar onde eles se encontram: na história social, na filosofia, na antropologia social e cultural, na etnografia, na psicologia e na psicanálise, mas também na literatura e na poesia (Ferrarotti, 2014, p. 25, apud Passeggi, Braga, 2014, p.152, grifos meus).

Essa longa citação de Ferrarotti sintetiza a essência desta terceira aposta. Entendo que o caráter de globalidade da narrativa autobiográfica é subjacente à inteireza do humano que a ciência fragmenta para estudá-lo. A consciência da historicidade resultante dos processos heurísticos e hermenêuticos subjacentes à reflexividades autobiográfica, faz apelo à uma mirada pós-disciplinar. Nesse sentido, o paradigma narrativo-autobiográfico facultaria a quem pesquisa o direito de ir e vir na busca de instrumentos heurísticos e hermenêuticos para melhor compreender o humano e sua ação no mundo. Trata-se de considerar como um direito universal, em pesquisa, navegar "na história social, na filosofia, na antropologia social e cultural, na etnografia, na psicologia e na psicanálise, mas também na literatura e na poesia”, para aprimorar o discurso científico (grafia) a favor da vida (bio) e de cada ser humano na sua singularidade (auto).

Ao considerar essas apostas em meu estudos, notadamente, quando passei a interrogar a reflexividade autobiográfica, na infância, dei inicio a estudos sobre as diferentes dimensões da constituição da subjetividade.

\section{O sujeito autobiográfico}

Para Delory-Momberger (2014), Theodor Shulze considerava a biografia em três níveis: "a biografia como realidade vivida (o bios), a biografia como texto, e a biografia como processo de formação" (2014, p. 331, grifos da autora). Nesse sentido, Schulze propõe a noção de sujeito biográfico no entrecruzamento de dois níveis: a "biografia como vida e a biografia como texto". Tenho preferido ultimamente denominar sujeito autobiográfico em função do que venho 
expondo até aqui. Quero propor que em cada um desses níveis se constituiria uma das dimensões da subjetividade: na biografia como vida, encontramos o sujeito da experiência, na biografia como formação o sujeito epistêmico, e na biografia como texto o sujeito autobiográfico que se constitui, na(s) e pela(s) linguagem (ns) numa estreita relação com o sujeito epistêmico e da experiência.

A inscrição do Oráculo de Delfos é inegavelmente uma referência no mundo ocidental: “Conhece-te a ti mesmo e conhecerás os deuses e o universo". Encontram-se nela amalgamados o sujeito do autoconhecimento (autobiográfico), "Conhece-te a ti mesmo!" e o sujeito do conhecimento (epistêmico). Assim, ao conhecer a natureza do ser humano, serás capaz de conhecer quem tem o poder (os deuses) e o que o rodeia (o universo). Mas, primeiramente, é preciso existir! Assim, surge o sujeito da experiência (empírico, de carne e osso). Sua singularidade, repousa na sua vida, na sua existência, que vai do seu nascimento à sua morte, nesse intervalo ele age e padece sob o impacto de leis biológicas e culturais, recompondo-se e se auto(trans)formando continuamente no ato de autobiografar.

Sobre o sujeito epistêmico e empírico muito já se escreveu, meu objetivo é apresentar o sujeito autobiográfico, justamente porque é muito timidamente que se dá a ele o direito de fazer sua entrada no mundo científico. O que gostaria de ressaltar, em primeiro lugar, é que o sujeito autobiográfico permite religar o sujeito epistêmico (abstrato, racional) e o sujeito empírico (da experiência).

Para Boaventura de Souza Santos (2002, p. 81), “A ciência moderna consagrou o homem como sujeito epistémico, mas expulsou-o enquanto sujeito empírico" o que levou a privilegiar o sujeito abstrato (racional, objetivo) em detrimento do sujeito empírico, concreto ( de carne e osso). Essa primazia, também expulsou a palavra da criança, da mulher, do negro, do pobre ... em função da "estreiteza" do seu pensamento, da insuficiência de seus modos de expressão, atravessada mais pela emoção do que pela razão. Entendo, portanto, que o sujeito da experiência age e padece no mundo, o sujeito epistêmico metaboliza as experiência na busca de uma lógica ou de coerência para suas ações e o sujeito autobiográfico metaboliza o que os dois outros lhe oferecem, transformando a experiência e o conhecimento numa narrativa, que o ajuda a agir e a interagir no mundo, com o outro e consigo mesmo. $\mathrm{O}$ que resulta para mim desse exercício filosófico sobre as três dimensões do sujeito - epistêmico, da experiência e autobiográfico - é que o sujeito autobiográfico religa no processo de autobiografização, o sujeito epistêmico e da 
experiência, oscilando e/ou priorizando um dos dois. Mediante o uso da linguagem (oral, escrita, digital, gestual, icônica...), ele se transforma em narrativa, poesia e história. Sua essência não é pois a vida (bios), mas a narrativa (texto), na qual e pela qual ele se torna um outro (reinventase). "Não sou pior, nem melhor. Por enquanto sou historicamente quem sou".

O estudo do sujeito autobiográfico nas abordagens narrativas pode se realizar em quatro grandes eixos (Passeggi, 2011). O primeiro eixo considera as narrativas autobiográficas como umfenômeno antropológico (Narrar é humano!). Ele responde à seguinte pergunta: Como cada ser humano se torna quem ele é? O segundo eixo utiliza as narrativas como método de investigação qualitativa, indagando-se sobre práticas e ações sociais, não para produzir conhecimento sobre elas, mas para perceber como os indivíduos dão sentido às suas ações no mundo (Escutar para compreender!), ele responde à pergunta: Como recolher e analisar fontes autobiográficas e o que fazer com elas? O terceiro eixo faz uso dessas narrativas como dispositivos de pesquisa-formação, instituindo a legitimidade do conhecimento (r)elaborado pela pessoa que ao narrar se forma (Narrar é preciso!). Ele responde à pergunta: Como a pessoa que narra se(trans)forma ao narrar? Finalmente, o quarto eixo estuda a natureza e a diversidade discursiva das escritas de si. Encontram-se aqui os estudos sobre as linguagens em que os humanos se dão a ler como narrativas produzidas nas línguas naturais (português, francês, tupi, iorubá, mandarim etc.) e em outros suportes semióticos: fotobiografia, videobiografia, iconografia, autobiografismo, ludobiogragrafia.... (Modos de narrar!) Esse eixo responde à pergunta: Como o humano se compreende e se deixa ler nos diferentes suportes semióticos narrativos.

\section{Considerações em aberto: promessas e incertezas}

Nós entendemos por consciência histórica o privilégio do homem moderno: o de ter plenamente consciência da historicidade de todo presente e da relatividade de todas as opiniões.

Hans-Georg Gadamer ${ }^{16}$

Um paradigma não é, em princípio, nem superior, nem inferior ao anterior, ele apenas responde melhor, provisoriamente, às interrogações diante do esgotamento de possibilidades das respostas oferecidas até então. Consciência da relatividade, como afirma Gadamer na

${ }^{16}$ Gadamer, 1996, p. 23. 
epígrafe acima, assenta-se no bom uso da reflexividade narrativa enquanto capacidade crítica para alcançar a consciência histórica, considerada, pelo autor, como um privilégio do homem moderno. Ricœur (1994), ao discutir a estreita relação entre tempo e narrativa, propõe uma "hermenêutica da consciência histórica", situando-a entre a permanência do passado no presente e o horizonte de expectativa, inquietações sobre o devir, incluindo o temor e a esperança. Essas são as promessas do trabalho autobiográfico crítico e reflexivo e dos desafios das apostas epistemológicas do paradigma narrativo-autobiográfico.

Em educação, a diversidade disciplinar, a multiplicidade de métodos, a confluência de teorias conduzem à coexistência de paradigmas, assim como convivem as pesquisas quantitativas e qualitativas para responder a questões humanas, organizacionais e de políticas governamentais. Mas é também inegável o quanto há de resistência às mudanças no edifício que se conseguiu, finalmente, erguer em educação com fragmentos de sua extensa diversidade: o ensino e suas especificidades, a organização curricular, a distribuição dos níveis de escolaridade, a percepção do desenvolvimento humano, a formação de professores, gestores, as políticas educacionais de gestão, inclusão, equidade, para os quais concorrem a história, a sociologia, a filosofia, antropologia, psicologia e as politicas públicas. Uma grande parte desse edifício foi construída com base em padrões de idade, de estágios de desenvolvimento, de modelos de transmissão/mediação de conteúdos escolares, com finalidades de preparar para o trabalho (ensino técnico profissionalizante) e/ou ensino superior (universidade). Dominicé (2010, p. 200) admite que teria se evidenciado em suas pesquisas que "a maioria das questões pedagógicas era organizacional antes de ser teórica: que a aplicação de modelos pedagógicos se fazia frequentemente não só desprezando os contextos de intervenção mas também ignorando as pessoas a quem essa ação se dirigia”. As crenças, normatizações e proposições que orientam a edificação dos aparatos educacionais têm também o poder de enclausurar a vida, a experiência de vida e suas conexões com a subjetividade de quem vive as aprendizagens, dissidências, sucessos, fracassos, medos, pressões e conflitos. Essa percepção da pessoa na sua singularidade faz parte de assuntos ditos transversais, dos quais a educação escolar se esquiva, e eles terminam por passar de fato despercebidos, inclusive por receio de doutrinação, catequeses, tabus. Nada é simples quando se trata de considerar a pessoa em formação na sua inteireza, e muito menos exigir dela uma expertise para a qual não recebeu formação. 
A humanidade vive, em 2020, uma virada, provocada pelas condições sanitárias postas a nu no enfretamento à pandemia mundial da covid-19, e longe estamos de perceber onde levará. Evito adentrar aqui nas especificidades da situação de calamidade pública em que se encontra o Brasil. Detenho-me no apelo a que se escreva sobre os impactos emocionais, sociais, afetivos, laborais... por ela provocados e a necessidade de buscar soluções para os desafios que conjuguem o diálogo entre educação e saúde, escola e família, estudantes e professores, para enfrentar tais impactos e os riscos do isolamento compulsório e prolongado, do abandono, mas também das mudanças na vida cotidiana de cada pessoa em seu habitat.

Ao longo do texto, defendi a tese da legitimidade de um paradigma narrativoautobiográfico e de um sujeito autobiográfico para a pesquisa e consequentemente para as práticas educacionais. Malgrado a dificuldade e a diversidade de questões envolvidas na construção do edifício educacional é importante que se atente para situações limites como a que se vive atualmente. A questão que sempre me pareceu não adequada é a opção pelo abstrato, ou a generalização (estudantes, professores, homens, mulheres, crianças, escolas, políticas) para tratar em educação dos seres humanos e estudar suas circunstâncias. A subjetividade só aparece quando se busca um rosto: Quem é? Quem foi? Seja para louvar ou para punir. E quando a pessoa surge na sua individualidade é que se percebe a relação entre o acontecimento, existência, resistência e a vida.

Defendi o escopo da subjetividade com o propósito de interrogar, justamente, o que dificulta seu ingresso nas ciências educacionais. Concordo que uma concepção subjetivista, individualista, intimista do sujeito pode ser reducionista, podendo justificar a sua ausência e a opção pelo objetivo. Mas, por onde andam Maria, José, Claudyane, Wesley, Lucas? Desaparecem na massa amorfa de alunos, estudantes, jovens que se dissolvem na generalidade. Do ponto de vista da pesquisa, concordo com Ferrarotti (2014, p. 106, grifos do autor) quando afirma que "a subjetividade imanente a qualquer narrativa ou documento autobiográfico porque, não o esqueçamos, os materiais utilizados são, em sua maioria, autobiográficos - é escamoteada por uma hermenêutica da biografia que só utiliza seus aspectos objetivos". Essa tipo de leitura dos documentos escolares também orienta as decisões e tende a atenuar a presença da subjetividade no discurso institucional.

A entrada da subjetividade em educação se dá de forma mais consistente no âmbito da formação, assim como foi o caso das histórias de vida em formação, que inspirou os trabalhos 
sobre a formação de professores. Falta interesse pela subjetividade ou nos faltam meios para levá-la a sério? Quando iniciei, em 1998, meus estudos sobre os memoriais, tipo de escrita de longa tradição no ensino superior brasileiro desde os anos 1930 (Câmara, 2012). Quando publiquei os primeiros resultados dessas pesquisas (Passeggi 2000), uma busca na Web, em 2000, o texto aparecia em primeiro lugar entre os dez ou 15 resultados encontrados. Por curiosidade, acabei de fizer uma busca, com o mesmo descritor, na Web, e o que se lê é: “Aproximadamente 12.500.000 resultados (0,31 segundos)".

Esse resultado encorajador desejo atribuir ao percurso das abordagens narrativas e do movimento biográfico, desenvolvidos por pesquisadores em âmbito internacional, responsáveis pela extensa literatura produzida nos últimos 40 anos. A dialética entre a vida, a experiência vivida e a ciência é a ideia central que defendemos como o fundamento central do paradigma narrativo-autobiográfico. Essas modestas considerações, em aberto, vão no sentido de destacar que os conhecimentos produzidos nas abordagens constitutivas do paradigma narrativoautobiográfico se enraízam na vida e na defesa da vida. O que válido para o indivíduo que narra é válido para sociedade e vice-versa.

\section{Referências}

Abrahão, M.H. (2004). (Org.) A aventura (auto)biográfica. Teoria e empiria. Edpucrs, Brasil.

Alheit, Peter; Daussien, Bettina. (2006, jan./abr.). Processo de formação e aprendizagem ao longo da vida. Educação e Pesquisa, São Paulo (volumen. 32, n. 1), p. 177-97.

Barthes, R. (1966) Introduction à l'analyse structurale des récits. Communications (8) pp.1-27, Paris, França, Seuil.

Bertaux, D. (2010). Narrativas de vida. A pesquisa e seus métodos. Trad. Zuleide Cavalcante e Denise Lavallée. Natal, Edufrn; São Paulo, Paulus.

Bolívar, A.; Segovia, J.D. (2019). La investigación (auto)biográfica en educación. Barcelona, Octaedro.

Brockmeier J.; Harré. (2003). Narrativa: problemas e promessas de um paradigma alternative. Psicologia: Reflexão e Crítica (volumen 16-3), p. 525-535.

Bruner, J. (1997). ... car la culture donne forme à l'esprit. De la révolution cognitive à la psychologie culturelle. Paris : Eshel.

Bruner, J. (1991, Autumn). The narrative construction of reality. Critical Inquiry, 18(1), pp. 121. Recuperado de https://www.journals.uchicago.edu/doi/10.1086/448619?mobileUi=0 A construção social da realidade. Trad. Waldemar Ferreira Netto. Recuperado de https://www.academia.edu/4598706/BRUNER_Jerome._A_constru\%C3\%A7\%C3\%A3o_ narrativa_da realidade

Catani, D. B.; Bueno, B. A. O. ; Souza, C. P. ; Sousa, M. C. C. (1994, n.1/2 ). Docência, Memória e Gênero: estudos alternativos sobre a formação de professores. Psicologia, volumen (4), pp. 299-318. 
Da Câmara, S. C. (2012, Julio 18 ). O memorial autobiográfico. Uma tradição acadêmica do ensino superior no Brasil. [Tesis de pregrado, dotorado]. Universidade Federal do Rio Grande do Norte, Natal, Brasil.

Delory-Momberger, C. (2005) La recherche biographique en éducation. Anthropos, Paris, França.

Delory-Momberger, C. (2000). Histoire de vie. De l'invention de soi au projet de formation. Anthropos, Paris, França.

Delory-Momberger, C. (2003) Biographie et éducation. Figures de l'individu-projet. Paris, França, Anthropos.

Delory-Momberger, C. (2014). Biografia e educação. Figuras do indivíduo-projeto. Trad. Maria Passeggi, João Gomes da Silva Neto, Luis Passeggi. Natal, Brasil: Edufrn Paulus.

Delory-Momberger, C. (2019). Vocabulaire des Histoires de Vie et de la Recherche Biographique. Toulouse, França. Érès.

Dominicé, P. (2000). L'histoire de vie comme processus de formation. Paris, França, L'Harmattan.

Dominicé, P. (2010). O que a vida lhes ensinou. In Nóvoa, A.;Finger, M. O método (auto)biográfica e a formação, , Brasil, Natal, São Paulo: Edufrn, Paulus.

Dosse, F.(2009). O desafio biográfico: escrever uma vida. Brasil: Edusp.

Ferrarotti, F. (2010). Sobre a autonomia do método biográfico. O método (auto)biográfico e a formação (pp. 31-57). Brasil, Natal, São Paulo: Edufrn, Paulus.

Ferrarotti, F. (2014), História e histórias de vida: o método biográfico nas ciências sociais. Trad. Maria Passeggi, Carlos Braga. Brasil, Natal, Edufrn.

Finger, M. (2014). As implicações socioepistemológicas do método biográfico. In Nóvoa, A.; Finger, M. O método (auto)biográfica e a formação, Brasil, Natal, São Paulo: Edufrn.Paulus, pp.189-222.

Freire, Paulo. (1992). Pedagogia da esperança: um reencontro com a Pedagogia do oprimido. Brasil, Rio de Janeiro, Paz e terra.

Gadamer, H-G. (1996). Le problème de la conscience historique. Paris, Éditions du Seuil.

Gusdorf, G. (1998). La parole. França, Paris, PUF.

Josso, M.-C. (2010). Experiência de vida e formação. Brasil, Natal, São Paulo: Edufrn; Paulus.

Nóvoa, A.; Finger, M. (2010) (Org.) O método (auto)biográfico e a formação. Natal, São Paulo, Brasil, Paulus, Edufrn,

Passeggi, M. C. (2016, jan./abr). Narrativas da experiência na pesquisa-formação: do sujeito epistêmico ao sujeito biográfico. Roteiro, Joaçaba, Brasil, (volumen. 41, n. 1), p. 67-86.

Passeggi, M. C. (2011, septiembre-diciembre). Aproximaciones teóricas a las perspectivas de la investigación (auto) biográfica en educación, Traducido del portugués por: Dora Lilia Marín Díaz, Revista Educación y Pedagogía ( vol. 23, núm. 61), pp. 25-40.

Passeggi, M. C. (2010). Narrar é humano! Autobiografar é um processo civilizatório. Invenções de vidas, compreensão de itinerários e alternativas de formação (pp. 103-130). Brasil: Cultura Acadêmica.

Passeggi, M.C. (2000) Memorial de Formação: processos de autoria e de (re)construção identitária. Recuperdo de https://www.fe.unicamp.br/eventos/br2000/india.htm

Passeggi, M.; Braga, C. (2014). Franco Ferrarotti: por uma humana ciência. In: Ferrarotti, F. História e histórias de vida: o método biográfico nas ciências sociais. Trad. Maria Passeggi, Carlos Braga. Brasil, Natal, Edufrn, pp. 151-155. 
Passeggi, M. C. y Souza, E. C. (2017). O Movimento (Auto)Biográfico no Brasil: Esboço de suas Configurações no Campo Educacional. Investigación Cualitativa, (2, 1), pp. 6-26. DOI: http://dx.doi.org/10.23935/2016/01032

Pineau, G. (2006, maio/ago) As histórias de vida em formação: gênese de uma corrente de pesquisa-ação-formação existencial. Educação e Pesquisa, São Paulo, Brasil (volumen 32, n.2).pp. 329-343.

Pineau, G. (2005, set./dez.).Emergência de um paradigma antropoformador de pesquisa-açãoformação transdisciplinar. Sáude e Sociedade (volumen.14, n.13), pp.102-110.

Pineau, G.; Le Grand, J-L. (2012). As histórias de vida. Trad. Maria Passeggi; Carlos Braga. Natal, Brasil, Edufrn.

Ribeiro, G. P.; Domingos, R. M. (2013, jan./jun.). A atitude antropofágica: devorar é a melhor maneira de significar. Ipotesi (volumen 17, pp. 69-80). Recuperado de http://www.ufjf.br/revistaipotesi/files/2011/05/Ipotesi_17.1-CAP07.pdf

Ricoeur, P. (1994). Tempo e Narrativa, Tomo I. Campinas, Brasil, Papirus.

Ricœur, P. (2010). Escritos e conferências 1: Em torno da psicanálise. Brasil, Loyola

Santos, B. de S. (2002). A razão indolente. Contra o desperdício da experiência. Brasil, São Paulo, Cortez.

Souza, E.C; Serrano, J.A.; Y Ramos, J.M (2014). Autobiografía y educación. Tradiciones, diálogos y metodologías. Revista Mexicana de Investigación Educativa, 62.3, Ciudad de México, pp. 683-694.

Schulze, T. (1993). Pedagogía con orientación biográfica. Educación. Colección semestral de aportaciones alemanas recientes en las ciencias pedagógicas (Vol. 48, pp. 78-100). Instituto de colaboración científica Tubingen.

Suárez, D. (2014). Espacio autobiográfico, investigación educativa y formación docente em Argentina. Revista Mexicana de Investigación Educativa. (19, 62), pp. 763-786, Mexico.

Kuhn, T. (1997) A estrutura das revoluções científicas. São Paulo, Brasil, Editora Perspectiva S.A.

Touraine, A. (1992) Critique de la modernité, Paris, França, Fayard. 